\title{
Sports in the French Association of the Paralyzed: difficulties in creating and maintaining a consensual policy
}

\section{Clément Gazza}

Santesih Laboratory, University of Montpellier, France

clementgazza@gmail.com

\begin{abstract}
The aim of this research is to provide a better understanding of the effects of a trying to create sports policy within an organization that is not familiar with this subject. Participant observation, plus 46 interviews, revealed the difficulties in setting up a real policy within the French Association of the Paralyzed. Because of heterogeneous points of view, the development of these activities remains more like roughly assembled guidelines rather than a real sports policy. Nevertheless, we should be able to obtain a consensus in creating awareness, in training and bringing the support people to use physical activities in their caring practices.
\end{abstract}

\section{KEYWORDS}

French Association of the Paralyzed; physical and sport activities; associative policy; partnerships; awareness; training

DOI

https://doi.org/ 10.14712/23366052.2017.3

(c) 2017 The Author. This is an open-access article distributed under the terms of the Creative Commons Attribution License (http://creativecommons.org/licenses/by/4.0), which permits unrestricted use, distribution, and reproduction in any medium, provided the original author and source are credited. 


\section{INTRODUCTION}

The French Association of the Paralyzed (APF) ${ }^{1}$, which was created in 1933, is the biggest French association relating to motor disabilities, with 25,000 members, 30,000 users, and 15,000 employees. It has the distinctive feature of having a double identity, both as a representative organization of disabled people and as an administrator for social and health establishments and services.

In sporting terms, even if initiatives already existed at the local level, it was necessary to wait for the associative project 2012-2017 for sport to appear for the first time in the text: "To promote access to leisure activities, to cultural and sport practices, to holidays, for everybody" (APF, associative project, p. 13). In March 2014, the APF materialized this desire by recruiting a PhD student to carry out research specifically concerning the question of physical and sports activities. The official aim was to study the sports activities which are proposed and practiced within the Association, in order to set up a suitable policy favouring access to sports for members and users.

The APF, however, remains an association which is far removed from sports institutions. Some authors have pointed out how paradoxical it is to involve sport, which is based on a production of the body, on speed, efficiency (Compte, 2003; Marcellini, 2005), on results and the "worship of performance" (Ehrenberg, 1991), in the field of disability, which itself is characterized by stigmatized bodies (Goffman, 1963), which need time and individual adaptations. It would be the "unexpected and paradoxical meeting between the world of excellence or performance and the lacking, the incapacity and the inefficiency" (De Leseleuc \& Marcellini, in Compte, Bui-Xuân, \& Mikulovic, 2012). What is more, the APF has no strong historic roots in the field of sport. Concretely, only 25 units out of more than $600^{2}$ have an employee specifically in charge of physical activities ${ }^{3}$ : "Sports practice is a secondary or even tertiary consideration [...] reflection about it is the matter of a few specialists" (Geoffroy, associative leader at the national headquarters $)^{4}$.

Thus, a sports policy is emerging, albeit within an organization which is not familiar with this subject. We can wonder how the various people affected by this change welcome it. How do they react to the introduction of sport into the debates? What points of view does it generate or reveal among these people? How can the APF take into account these various points of view in elaborating a national sports policy? How is this policy elaborated and conducted between the national level and the local level of the Association?

In French: 'Association des Paralysés de France'.

2 This figure includes the departmental delegations, the social and health services, and holidays organized by the APF.

3 Most of them have an 'adapted physical activities' license.

4 Informal interview carried out on 5th of April 2016. 


\section{METHODOLOGY}

\section{Research position}

The initial order from the APF was relatively broad, and the research was carried out as a kind of research-action. That is why we started with an exploratory qualitative approach, specifying our research subject as more data became available (Morin, 1985; Olivier de Sardan, 1995; Beaud \& Weber, 2010). Thus, an inductive approach was used (Warshay, 1975; Creswell, 2012), which was facilitated by our research position as an employee of the association.

\section{Tools}

We have been undertaking participant observation at the national headquarters of the APF for three years. During this time, a day-to-day diary has been kept, reporting all the data relative to our study. In parallel, we have been immersed within ten local units for an in-depth analysis at the local level. Mostly, we spent approximately one month in each of them, until the data became "saturated" (Glaser \& Strauss, 1967). Likewise, a diary was kept for all these local units.

At the national headquarters, as in the APF units, interviews were carried out with the various actors of the Association, half with members and users, and half with associative leaders, employees and volunteers. The interviews lasted one hour and thirty minutes on average, and were led through open-ended questions as much as possible ${ }^{5}$. Our analyses through this paper are supported by 46 interviews which have been entirely transcribed verbatim.

Finally, we regularly referred to the official documents (associative project, APF Charter, APF Plea, projects of establishments, etc.), as well as the diverse internal communication tools (circulars, the collaborative platform, the official magazine of the Association ${ }^{6}$ ).

\section{Data analysis}

All the data collected (observations, interviews, official texts of the APF) brought a diversity of sources, which were examined according to the principle of triangulation (Denzin, 1978; Patton, 20017; Glesn, 2011, p. 478).

All our data were ordered by themes in connection with our subject. This ranking allowed us the better to compare speeches and practices between the various actors, according to a comprehensive approach (Kaufmann, 2007). It also fostered the linking between sources, which highlighted the strengthening or the contradictions. In addition, we could provide responses to our questions by using the technique of analytical questioning (Paillé \& Mucchielli, 2008).

5 Some disabled people could have difficulties with speech, situating events in time or projecting into the future. In these cases, we sometimes had to adopt more semi-structured forms.

6 Called 'Faire Face' (meaning Face up).

7 Quoted by Devaux-Spatarakis and Gregot (2012).

8 Quoted by Richard (2013, p. 89). 


\section{The difficulty of defining a consensual sports policy Differences in expectations about sport disciplines and practice terms}

During the interviews, the members and users expressed different expectations about sport practice: forming social links, health concerns, gaining autonomy, well-being, and sometimes just to pass time. Their expectations for sport disciplines were also very different, so that none really stands out individually: competitive sports, soft gymnastics and extreme sports are equally represented in the members' and users' expectations. This diversity is not surprising since the APF was not built around sports: there is thus no reason for having a common sporting culture, nor for finding the same diversity as in the rest of the population.

Expectations in terms of goals and sports disciplines are so heterogeneous that it is difficult to find a consensus and to define a guideline. The APF is meeting this great diversity by working with several sport partners. However, when we started as a development agent, an APF department head drew our attention to the fact that we should avoid multiplying the partners in order to work more in depth with each one of them. As a consequence a dilemma appeared, consisting in having to choose between two ways:

- The first way is to favour a small number of partners in order to work thoroughly on the accessibility possibilities, at the risk of limiting the diversity of sport disciplines on offer.

- The second way is to take into consideration the diversity of people's demands, at the risk of becoming less efficient in making accessible any specific one.

Today, the APF is at the crossroads of these two possible paths. The first one seems to be the simplest: by working with two or three fixed partners and by providing a well targeted offer, developing possibilities would be considerably facilitated. This approach could lead to the emergence of an internal 'common sports culture' within the APF. Regulating demands would allow the APF to realize a more in-depth work with partners and thus to develop the accessibility to certain sports to the full. Their access could be particularly well thought out and organized, which would allow members and users to benefit from a better structured offer. Finally, the advantage of this way is that members and users might speak with a common voice. As a consequence, they would have more weight in their sporting demands: because of the number of potential practitioners, and this might multiply the chances of obtaining an offer corresponding to their demands.

However, this construction of a common sports culture would be in conflict with the associative project document, which emphasizes the necessity of a 'personalized approach'. In this document ${ }^{9}$, paragraph $\mathrm{n}^{\circ} 4$ entitled "For a service as close as possible to the people and their needs" asks us to "take into account [...] their personal projects." As the goal of the association is to individualize the offers as much as possible and to provide personalized answers to each request, it may seem inappropriate to work with only two or three partners. This would not meet the diversity of the demand. Actually, the APF has adopted a hybrid position, with a first circle of main partners, and a second circle consisting of more occasional collaborations.

APF, associative project 2012-2017: 'Move the lines! For an inclusive society'. 
Another solution is to work with partners who already provide a diversity of sports offers, either because they are multi-sports federations or because they provide both competitive and recreational sports. Thus, the four sport partners which are the closest to the APF are actually multi-sports federations. Lastly, the third solution is to work with organizations which serve as intermediary between the APF and many sport partners. For example, this is the case of the association DAHLIR ('plan supporting the disabled into integrated and regular leisure activities' $)^{10}$, that aims to collect requests concerning leisure activities by disabled people and finding solutions for a facilitated and sustainable access. In the same way, the PAIPS ('individual support path into sport practice' $)^{11}$ is a more recent plan set up by some decentralized services of the Ministry in charge of sports. It has the same goal, specifically concerning physical and sport activities. Several times, as a development agent, we met people in charge of DAHLIR or PAIPS in order to convey sport offers to APF's members or users more easily.

\section{Differences in the goals attributed to the organization of physical activities}

The difficulty in choosing sport partners can also come from differences over the goal which is aimed at sports. This was the case when the APF Board meeting debated and discussed the place that should be granted, within the collaboration, to the French Handisport Federation $(\mathrm{FFH})^{12}$, a sport federation specifically dedicated to people with a physical or sensory impairment. This is therefore a case of practicing sports between disabled peers, which was precisely the point which divided the administrators.

Most of them welcomed the partnership with Handisport, given that it has major technical expertise in the field and that it meets the needs of people with severe disabilities who can't always find a place in ordinary clubs. Nevertheless, other administrators, with a more radical point of view about social inclusion, preferred to concentrate efforts on the development of mixed sport practices, within the community and with non-disabled people. One administrator said: "At the end of the meeting [with Handisport], I wondered if it was the right interlocutor for the APF." To such administrators, the partnership with the APF represented a detour with regard to the aim of inclusion, which is the central notion of the APF's associative project.

At this point, we should investigate the concept of 'inclusion' in order to understand better the beliefs that the actors have developed towards it. Indeed, we have noted large differences in its definition, or at least in the way it is perceived in the context of physical and sport activities. Inclusion is the central concept in the APF's associative policy, as shown by the title of the associative project 'Move the lines! For an inclusive society' (APF, 2012-2017) ${ }^{13}$. However, not all the actors share the same beliefs about the concept of 'inclusion' or 'inclusive society'. Our focus on the physical

10 In French: 'Dispositif d’Accompagnement du Handicap vers des Loisirs Intégrés et Réguliers'.

11 In French: 'Parcours d'Accompagnement Individualisé vers les Pratiques Sportives'.

12 In French: 'Fédération Française Handisport'.

13 Published on the web: http://www.apf.asso.fr/left-presentation/left-presentation-projetassociatif. The aim is to move the lines of engagement towards a more inclusive vision of society, including the development of a range of services that are 'closer to people'. 
activities enabled the revelation of these differences. We shall give two examples to illustrate this idea.

The activity boccia ${ }^{14}$ is provided in a residential unit for adults. Training takes place once a week. The group is composed of the sports instructor, who is a professional of the residential unit, and on average six players, who are users of the establishment. Thanks to adapted minibuses, everybody goes to a city gymnasium, made available by the City Hall. Whereas the activity could be organized within the establishment, to save time on transport, the sports instructor asserts that it is important

"to get out of the walls of the establishment": "behind this idea of inclusion, there is the strong idea getting out of the residential shelter, not staying between four walls dedicated to disability and to go, to go towards the others. Forgetting about a part of one's disability, to be just like everybody" (Pierre-Matthieu, sports instructor).

Almost all the physical activities take place outside of the establishment, but the athletes very rarely mix with non-disabled people. They do indeed go outside of the "four walls dedicated to disability", but we can wonder if, in this case, they manage to get out of the "institution of disability" (Barral et al., 2000) which simply moves from one place to another.

According to some other actors, the goal of inclusion involves a very different belief. A local delegation ${ }^{15}$ accompanies its members on a weekly outing to an ice rink. A time slot is specifically reserved for them. This local delegation offered to one of the APF's establishments also to accompany its users. The director of this establishment refused on the ground that it is not an 'inclusive' activity according to her, as there is no mixing with other people. In this case, the director considers that inclusion necessarily involves mixing with non-disabled people, and that going somewhere other than within the establishment is not enough to count as an 'inclusive' activity.

Through these two examples, we can observe two very different beliefs coming up against each other on the concept of inclusion. These differences render a consensus difficult to obtain, on the ways to meet the goal of inclusion. These debates are rather natural and healthy in the life of all big organizations, but for sure, they cause some discomfort in defining a guideline for the associative policy. How can a consensual policy be developed for actors who do not share the same beliefs concerning the objectives and the ways to implement them? How do we define guidelines which are supposed to gather together beliefs and practices which seem incompatible? Are we not facing a dilemma which consists in either defining an empty policy allowing all the attitudes, or establishing a real position but at the risk of antagonizing half of the people involved?

14 This is a game of precision which consists in throwing a ball closest to the white ball called 'jack'. This sport was created especially for disabled people, with specific adaptations for those who cannot move their arms.

15 The delegations are not establishments or services funded by public authorities. They are the local relays of the associations, which gather members and can offer them leisure activities. 


\section{A lack of dialogue as a fertile ground for misunderstandings}

Sport does not hold a central position among the debates in the APF. It does not benefit from the same attention as other subjects, such as accommodation, access to employment, the income of disabled people, and accessibility to public places and to transport, which are recurring subjects for the decision-making authorities (APF Congress, Board meetings, General Assembly or departmental meetings) or in communication outlets (the magazine of the association 'Faire Face', the circulars, the internal collaborative platform, etc.). For example, at the end of an APF Board meeting which lasted all day long, we had only five minutes to present two agreements, prepared with two out of the four main sport partners of the APF. The administrators voted for this partnership with only the data provided through this short presentation. In this context, we understand that the decisions which must constitute the sports policy do not undergo lengthy debates, confrontations of points of view, precision concerning certain data, or sharing and revising opinions. As a consequence, it is not surprising that the differences underlined above remain strong. Furthermore, they cannot be dissipated as long as the subject is not much, or not at all, discussed. There are still disagreements, differing points of view, sometimes without the people concerned even realizing it. This lack of dialogue must contribute to the misunderstandings which we highlighted above, and may even strengthen them. The lack of time spent on the subject of sports must increase the difficulty of developing a consensual policy.

The differences in expectations and beliefs, as well as the lack of dialogue, make difficult the elaboration, on a national scale, of a consensual sports policy. In this context, the internal official texts of the APF remain necessarily broad on the subject of sport. The associative project simply introduces the objective "support [its] access" (APF, associative project, p. 13), by linking it with cultural practices and with holidays. Likewise, most of the official texts only mention sport by linking it with the problem of accessibility and by including it in the triptych 'culture-sports-leisure'.

Consequently the development of a sports policy remains a complex problem, which is resolved for the moment only by broad or even vague guidelines. All the same, these allusions draw attention to the subject, even though it is not enough to be considered as a real policy. Furthermore, we shall see that, even when choices are clearly defined, the differences in beliefs between the national level and the local level also complicate the implementation of a sports policy in the field.

\section{The implementation of the sports policy at the local level Implementing the partnerships}

The national headquarters of the APF got in touch with the FFH at the beginning of the year 2014. Local partnerships had already existed for a long time between these two organizations. The place where these links were identified with the most intensity was in a rural region, the inhabitants of which regularly qualify it as a 'human scale region'. Its main city has a population of only 18,600 inhabitants and the diverse actors of the APF frequently explained that, in this place, 'everybody knows each other'. The APF delegation lends its premises for FFH meetings, the FFH organizes sport initiatives for the APF's members, and each organization attends the other's assemblies. However, this kind of partnership involves actors who are personally close, who have known one another for a long time and who have social relationships besides their respective 
labels APF and FFH. Thus, we can suppose that these close links are rather due to the people themselves than because of an APF-FFH collaboration induced by a real policy.

Nevertheless, although some actors did not wait for the national impulse to develop partnerships on the local level, others seem to be watching and waiting for an impetus on the national level. Through our participant observation, we met a regional manager of the APF, who had also been involved for a long time in the FFH. This actor questioned and regretted that the APF and the FFH did not have closer links:

As a director [of an establishment], we don't always know which position to take with regard to the FFH. It would be good to know that the associative leaders give their consent, that it comes from the top and that they would tell us 'you have everything to start, you are authorized' (Hervé, regional manager).

Through this example, we have an actor in the field who is waiting for instructions from the national headquarters to know which position to hold concerning local partnerships. On the other side, a national manager informed us that the APF must exploit the local initiatives as a starting point for its policy because "the field does not like to be given orders". In this situation, the regional manager is convinced that the APF should follow a traditional top-down structure, whereas the national manager sees it as a bottom-up organization. A fresh source of misunderstanding therefore appears since each actor waits for the other to take the initiative to develop the partnership - the first one for fear of exceeding the limits of the Association's guidelines, and the second one for fear of being too authoritarian.

A national agreement between the APF and the FFH was signed in October 2016. Several lines of cooperation are planned through it: sport initiatives within social and health establishments and services, mutual training for professionals concerning physical activities and disability, lending specific equipment, informing and making disabled people aware about physical activities, individual support relating to sports requests, etc. The agreement also established free access for any member of the APF wishing a FFH license, and vice-versa. We are following with interest the possible impact of this agreement on local practices. Will local partnerships become easier to form now that the national partnership is official? On one hand, we can expect that, thanks to the communication of the national headquarters towards its units, this agreement will open the path for new ideas at the local level for the actors in the field. On the other hand, an official text from the national headquarters may be insufficient to change the outlook and the practices developed by the actors in the field concerning physical activities. In fact, a text produced at the national level will be accepted and backed by the actors in the field only if they share a minimum number of beliefs and values with both the national headquarters and the text in question.

\section{Between national and local levels, between medical and social models}

In the various units of the APF, we have often heard that the development of sport is awkward or impossible because "people are too severely disabled", or because it concerns the issue of "ageing practitioners". Referring to the model of the International Network on the Disability Creation Process (figure 1), we could assert that the explanations are more relative to personal factors rather than to environmental factors. 


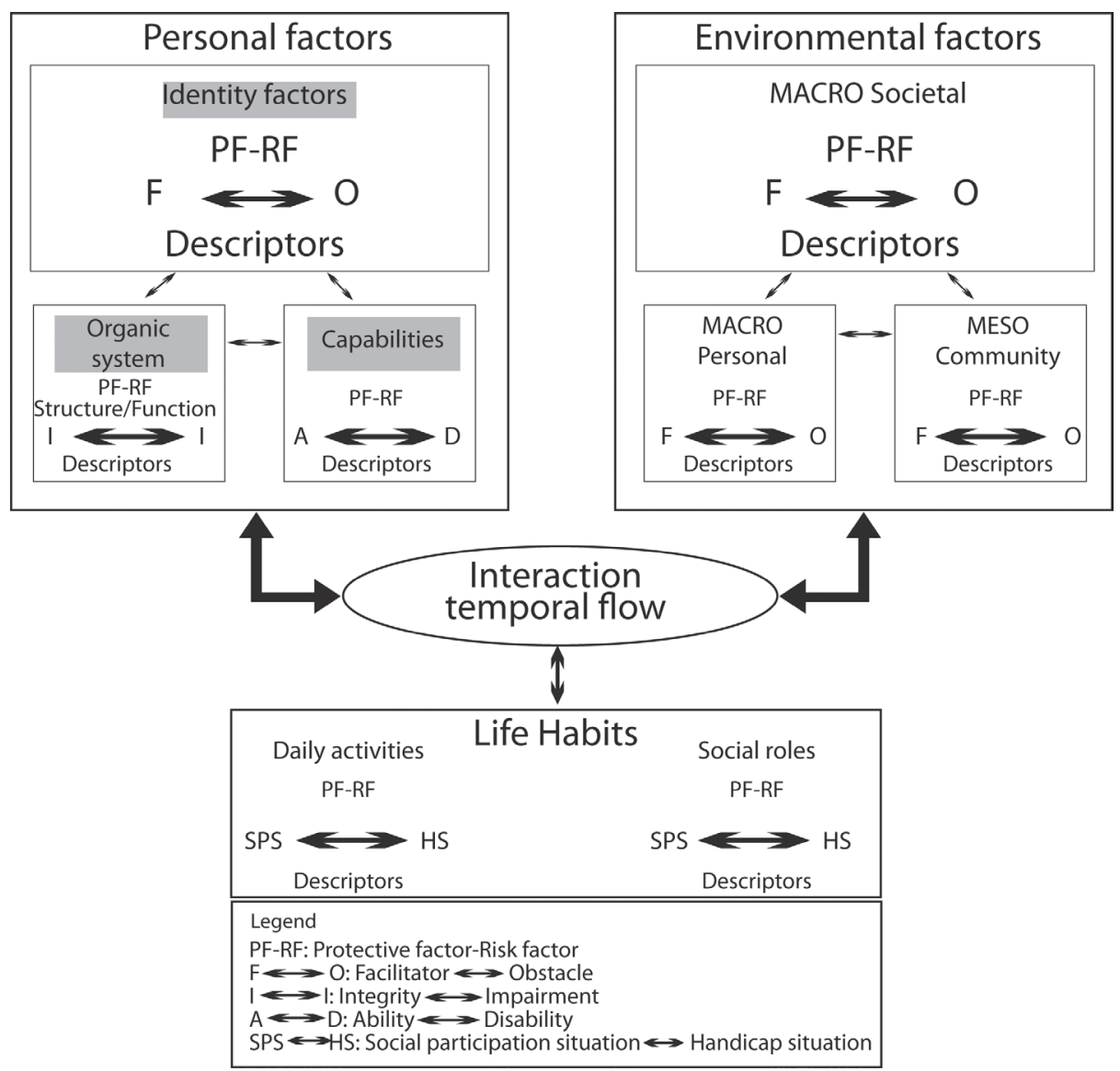

Figure 1 Human development model - disability creation process (HDM-DCP). Translated from: Fougeyrollas (2010). Published at https://www.researchgate.net/figure/272029642_fig1_Figure-1-Human-development-model-disability -creation-process-HDM-DCP-Translated

This outlook clearly contrasts with the philosophy and the values developed by the $\mathrm{APF}$, which has always based its claims on issues linked to environmental factors rather than to personal ones. The APF calls for the development of public places to build "a society which is open to everybody" (an expression which can be found in the associative project and in the Plea $\mathrm{APF}^{16}$ ). The association thus attributes disability not to the actual person, but to the environment which is not adapted to him/her and which puts the person in a "situation of disability". On this topic, the APF refuses the terminology "handicapped person" or "disabled people", but systematically uses the expression "person in a situation of disability". The agreements with sports partners are part of this approach, in trying to act on every environmental factor: transport, human help, awareness of promoters, adapted sport equipment, financial accessibility, etc.

16 Published on the web: http://plaidoyer.blogs.apf.asso.fr. 
Besides, the interviews with professionals and volunteers do not show a conflict or a disagreement on this subject with the organization: on the contrary, in their speeches, the interviewees widely share the idea that society produces the situations of disability and that the environment is essential so that the person can lead life "just like everyone else". In other words, the professionals and the volunteers of the APF, in the same way as the official speech of the association, advocate a "social model" of disability and widely reject the "medical model" (Brisenden, 1986). In this case, how can the barriers identified as "too severely disabled" or "ageing people" be compatible with the philosophy of the APF and with their own outlook, which demand a social model of disability?

If the issue does not come from a disagreement between the actors of the APF and the official discourse of the institution, we must explore more deeply the contradictions within the views expressed by the professional and the volunteer care attendants. The interviews highlight that, even if the actors clearly approve the social model, they frequently identify barriers in the access to the physical activities which they often attribute to the people themselves. In that situation, we observe a continuation of the medical model whereas the national policy is resolutely positioned towards the social model. Thus, the actors in the field have the impression of being confronted with individual limits and that the environment will not make everything possible.

We shall take the example of a sports instructor working in a residential shelter for adults, with whom we spent one month. When talking, he often explained to us the necessity of adapting physical activities to the needs of the person. These were not empty words: we observed that he indeed put them into action during his sports sessions. Nevertheless, he expressed his limits during his interview:

We should be there for them and we don't find [...] we don't really find solutions so [...] well, for Marc and Martine it's alright, but Madam M. who is over there, her health [...] her health doesn't allow to do much [...] so that's difficult. Except playing chess with her, I don't really see what else to do! (Pierre-Matthieu, sports instructor, employee and graduate in Adapted Physical Activity)

This sounds as if the professional feels powerless in the face of the challenge of adapting the activity to the needs of the person. Even if he subscribes to the general principle, some cases considered as extreme allow the personal factors, at least with regard to his beliefs, to get the upper hand over any other consideration. In some cases, the continuation of the medical model can even appear as a way to clear oneself of responsibility: as a professional or volunteer, if I do not propose physical activities, it is not because I did not know to set in motion, it is not because I am not able to organize them, but it is just because the people of whom I take care are not able to take part in such practices.

In this context, the APF has many difficulties in broadcasting the social model of disability which it develops and which it would like to be applied in the field. The sports policy, in the same way as the general policy of the APF, advocates and emphasizes certain beliefs both about disability and about the way in which to support disabled people. Our inquires show us that these guidelines are not necessarily respected in the field, even though the actors share the beliefs developed by the national model. 
We can then think that the role of the national policy is to provide tools which will enable them to respect and to apply the philosophy of the associative policy in general. This involves making an effort to raise awareness of the actors in the field, but also to train them so that they actually have the means to adapt the environment to the needs of the person. It also involves material and financial resources. This last point exceeds our line of research, but we shall go back to the first two points.

\section{The necessity of raising the awareness of care attendants}

This latter example referred to Pierre-Matthieu, a sports instructor. He was trained at the university for an Adapted Physical Activity license, was specifically recruited for a sports mission, and has 27 years of experience in this job. Unlike him, most of the professionals and volunteers in the APF - whose job is not primarily linked to sport have not been trained for these activities, and they are not necessarily sport practitioners themselves. As they do not come from the sports field, they do not necessarily intend to propose the introduction of a physical activity to the public which they care for, because they may not perceive all of the benefits for them in terms of health, social participation, inclusion in the community, perception of quality of life, or acquisition of adaptive skills (Badia, Orgaz, Verdugo, \& Ullan, 2013). It is also difficult for them to know what these people are capable of, as well as their limits in terms of practice. This could lead to dangerous situations, but most of the time, fear of danger or accidents leads them to avoid any risk-taking and dissuades them from engaging in the organization of physical activities. For instance, this is the case in some local delegations which do not propose outings to the swimming pool or to the seaside, because the responsibility and the risk are considered too high.

Thus, the sports policy of the APF aims at making professionals and volunteers aware of the use of physical activities and promoting their integration into their practices. Firstly, it is a case of understanding and familiarizing them with the social model of disability. But this part does not seem to be the most difficult part, since the large majority of APF actors seem ready to adopt this model. The crucial part is being able to apply this model to physical and sport activities by demonstrating that it is possible to adapt them to the needs of the people in their care. To this purpose, the sports policy of the APF is based on the expertise of certain sports partners who are able to propose adapted activities to disabled people. For instance, we can mention the 'Cap Loisirs Sportifs' plan (meaning 'Sportive Leisure Cape') provided by one of the main partners of the APF, the National Union of Outdoor Sports centers (UCPA) ${ }^{17}$. It consists of mobile sports facilities that could be carried inside the APF units. The aim of this is to create a first link between the various sports possibilities and disabled people, and to promote and support a possible transition towards a sport practice integrated within the community. In the first stages, cycles of five two-hour sessions are proposed, which are supervised both by sports instructors from the UCPA - who are professionals specifically trained in adapted physical activities - and by the professionals from the establishments and social services. On the APF's side, this type of plan can allow professionals to perceive ways of organizing these physical activities. They can help to realize the extent of the capacities of the users in action and possibly

17 In French: 'Union nationale des Centres sportifs de Plein Air'. 
contribute to modifying their beliefs. At the national level, the APF tries to support and sustain this kind of plan by promoting them within its internal network and by allowing their organizers to present them in action during national meetings.

\section{The necessity of training the support people}

Nevertheless, inciting the professionals and the volunteers to use physical activities has no sense if these actors do not have a minimum amount of skills in organizing them. Most of the time, the sports activities in social and health establishments and services are provided by educators, animators or medical and psychological assistants who have no specific mission aimed at sports. As a consequence, the care attendants who have no sports culture, or at least no specific training, can be quickly dissuaded by feeling powerless in organizing and adapting physical activities. Professionals who have no specific sportive training are the most common case in the various units of the APF. Considering themselves as ineffective, the actors risk developing the feeling that they have come up against barriers due to personal factors, not knowing how to adapt the environment or how to adapt a physical activity to the needs and capacities of the person.

If the sports policy of the APF does not bring a minimum amount of knowledge concerning the organization of adapted physical activities, the support people will always be placed in a complicated position. They will never know how to adapt sports tools because of a lack of training and skills surrounding their use. Thus, the sports policy of the APF must plan to provide ways to its professionals and volunteers to use physical activities as a tool in caring for disabled people. It does not mean that all the care attendants should become specialists in the field of physical activities, but the actors who are the most likely to organize them should be taught the basic skills for organizing these activities safely. They should also be able to adapt physical activities to the capability and individual needs of each disabled person. Of course, as was proven by the example of the sports teacher who was mentioned above, a long and specific training does not necessarily mean success in overcoming all the obstacles, but a minimal training could quickly contribute to the development of this tool within the units of the APF (social and health establishments and services, but also departmental delegations or holidays organized by the APF).

There again, the APF plans to rely on its sports partners to develop the training of its staff for physical activities. This approach is at the moment only at its beginning, but the agreement signed or planned for with the FFH and the UCPA aims precisely, amongst other topics, at initiating this minimal training for some professionals or volunteers of the APF. In return, the APF has some expertise in terms of accessibility or knowledge concerning disability in general, which can interest these partners and which can help them to develop activities which are more and more accessible for disabled people, including members and users of the APF. Thus, the sports field and the disability field can mutually strengthen their skills, which should benefit the public they care for. 


\section{CONCLUSION}

We started out from the observation that defining and implementing a national sports policy is particularly difficult within an organization which is quite far removed from the sports field. It seems difficult to define a consensual policy as the goals, and the ways to reach them, are diverse among the various actors of the APF. From this point of view, choices made at the national level often seem more like roughly assembled guidelines rather than a real policy. However, a more clearly-cut positioning could concretely bring up the issue for all the actors of the APF. It would probably be difficult, or even impossible, to develop a consensual policy, but the elaboration of a policy could bring up subjects that would be useful for a constructive dialogue. Furthermore, it would certainly be difficult for actors in the field to apply this sports policy in its entirety, but it could set a target to aim at. This target may be a utopia, but one that is necessary because it would offer a guideline for the various actors.

The APF does not have sufficient expertise alone to support its network in the implementation of this sports policy. This is why the APF chooses to rely on its sports partners to raise awareness, train and engage the actors who are open to using physical activities in their caring practices. The success of this sports policy would also be a good point for the sports partners because this large association allows them to touch a higher number of potential practitioners. The work put into these partnerships could then be the cornerstone in the construction of the sports policy of the APF.

\section{REFERENCES}

Badia, M., Orgaz, M. B., Verdugo, M. A., \& Ullan, A. M. (2013). Patterns and determinants of leisure participation of youth and adults with developmental disabilities. Journal of Intellectual Disability Research, 57(4), 319-332.

Brisenden, S. (1986). Independent Living and the Medical Model of Disability. Disability, Handicap and Society, 1(2), 173-179.

Beaud, S., \& Weber, F. (2010, 1st ed. 1997). Guide de l'enquête de terrain. Paris: La Découverte.

Bouttet, F. (2015). Organiser la pratique sportive des personnes handicapées. Entrepreneurs et dynamiques institutionnelles dans la construction de l'action fédérale. Doctoral dissertation. University of Strasbourg, France.

Compte, R. (2003). Le sport pour handicapés mentaux : ouvrir aujourd'hui pour demain le débat éthique. Empan, 51, 68-73.

Compte, R., Bui-Xuân, G., \& Mikulovic, J. (2012). Sport adapté, handicap et santé. Montpellier: FFSA \& AFRAPS.

Creswell, J. W. (2012). Qualitative inquiry and research design: Choosing among five approaches. London: Sage publications.

Devaux-Spatarakis, A., \& Gregot, A. (2012). Les défis de l'emploi de l'étude de cas en évaluation. Politiques sociales et familiales, 110(1), 33-44.

Ehrenberg, A. (1991). Le culte de la performance. Paris: Calmann-Lévy.

Glaser, B., \& Strauss, A. (1967). The Discovery of Grounded Theory: Strategies for Qualitative Research. Chicago: Aldine de Gruyter.

Goffman, E. (1963). Stigma: Notes on the management of spoiled identity. Englewood Cliffs: Prentice-Hall.

Kaufmann, J. C. (2007). L'enquête et ses méthodes. L'entretien compréhensif. Paris: Armand Colin. 
Marcellini, A. (2005). Des vies en Fauteuil ... Usages du sport dans les processus de déstigmatisation et d'intégration sociale. Paris: CTNERHI.

Marcellini, A., \& Villoing, G. (2014). Corps, Sport, Handicaps. Le mouvement handisport au $X X I^{\text {eme }}$ siècle. Lectures sociologiques. Vol. 2. Paris: Téraèdre.

Martel, L. (2010). Les politiques d'insertion par le sport du MJS entre 1981 et 2002. Analyse comparée de deux publics, les jeunes des quartiers et les personnes handicapées. Paris: Editions Connaissances et Savoirs.

Morin, A. (1985). Critères de "scientificité" de la recherche-action. Revue des sciences de l'éducation, 11(1), 31-49.

Olivier de Sardan, J. P. (1995). La politique du terrain. Sur la production des données en anthropologie. Les terrains d'enquête, 1, 71-109.

Paillé, P., Mucchielli, A. (2008). L'analyse qualitative en sciences humaines et sociales. Paris: Armand Colin.

Pôle Ressources National Sport et Handicaps (2010). Etude sur la prise en compte du handicap au sein des fédérations sportives. Retrieved 14.09.2016 from: http://www.handicaps .sports.gouv.fr/images/stories/fichiers/prnsh/productions_prnsh/2010-Etude_PRNSH _Fedes.pdf.

Richard, R. (2013). L'expérience sportive du corps en situation de handicap. Approches praxéologique et socio-phénoménologique du foot-fauteuil. Doctoral dissertation. University of Paris Descartes, France.

Ruffie, S., \& Ferez, S. (2013). Corps, Sport, Handicaps. L'institutionnalisation du mouvement handisport (1954-2008). Vol. 1. Paris: Téraèdre.

Warshay, L. (1975). The Current State of Sociological Theory: a Critical Interpretation. New York: McKay. 